Running Head: Implicit theories and representativeness

Implicit theories and offender representativeness in judgments about sexual crime

\author{
Craig A. Harper ${ }^{1 *}$ \\ Ross M. Bartels ${ }^{1}$ \\ ${ }^{1}$ University of Lincoln, UK
}

* Corresponding author: Craig Harper, School of Psychology, University of Lincoln, Brayford Pool, Lincoln, LN6 7TS.

E-mail: craigaharper19@gmail.com

Online first citation: Harper, C. A., \& Bartels, R. M. (2016). Implicit theories and offender representativeness in judgments about sexual crime. Sexual Abuse: A Journal of Research and Treatment. doi: 10.1177/1079063216658019 


\begin{abstract}
Implicit theories structure the way people understand and respond to various human actions. Typically, people believe attributes are either fixed (entitists) or malleable (incrementalists). The present study aimed to examine: (a) whether attitudes towards sexual offenders differ depending upon one's implicit theory about human nature and sexual offenders, and (b) whether implicit theories are associated with judgments made about different types of child abuser. A sample of 252 community participants was recruited. Their attitudes, implicit theories, and political orientation were assessed via self-report. One of three vignettes describing an incidence of child sexual abuse was then presented. The cases were identical except the perpetrator was either an adult male, an adult female, or a male juvenile. Participants then made judgments about the offender's deserved sentence and moral character. Entitists (across both domains) held more negative attitudes than incrementalists, although the magnitude of the difference was greatest when examining implicit theories about sexual offenders. Compared to those with an incremental theory of sexual offenders, entity theorists judged sexual offending to be more: (a) indicative of the perpetrator's moral character, and (b) deserving of punishment. However, scores were greater towards the adult male relative to the adult female and juvenile. The findings suggest that implicit theories about sexual offenders are domain-specific. They also indicate that judgments made by those with an entity theory (about sexual offenders) are affected by whether a case is representative of a stereotypical sexual offender. Implications of the findings are discussed, along with limitations and future research.
\end{abstract}

Keywords: implicit theories; representativeness heuristic; sexual offenders; public attitudes; schema 


\section{Implicit theories and offender representativeness in judgments about sexual crime}

Much research has demonstrated that people generally hold more negative attitudes towards sexual offenders than perpetrators of other crime types (e.g., Rogers \& Ferguson, 2011; Willis, Levenson, \& Ward, 2010). Given the nature and damaging consequences of sexual crime, it is not surprising that people within society hold such attitudes. Sexual offenders and the type of offenses they commit elicit negative affective reactions, such as fear, disgust, and moral outrage (Kernsmith, Craun, \& Foster, 2009; Vess, 2009; Willis et al., 2010), which can provide the basis for one's negative attitude towards sexual offenders; a phenomenon known as ‘affect-as-information' (Clore, Gasper, \& Garvin, 2001).

People have a striking ability to effortlessly form attitudes on the basis of "media exposure, and other forms of socially-supplied information" (Crano, Cooper, \& Forgas, 2010, p.3). Therefore, media coverage about sexual offenders is likely to play a major role in shaping the public's attitude towards sexual offenders (Craun \& Theriot, 2009; Galeste, Fradella, \& Vogel, 2012; Harper \& Hogue, 2015a; Malinen, Willis, \& Johnston, 2013; McCartan, 2010; Quinn, Forsyth, \& Mullen-Quinn, 2004; Thakker, 2012). This is because such information is sensationalized, selective, and biased, creating a skewed representation of whom or what a sexual offender is (Greer, 2012; Harper \& Hogue, 2014). Indeed, the public endorse numerous incorrect beliefs (or myths) about sexual offenders that are thought to be shaped by the media. These include believing that sexual offenders are: homogenous, primarily strangers, predatory, re-offenders, specialists, resistant to treatment, products of early abuse, mentally ill, and/or 'dirty old men' (Cromer \& Goldsmith, 2010; Fedoroff \& Moran, 1997; Fuselier, Durham, \& Wurtele, 2002; Galeste et al., 2012; Sanghara \& Wilson, 2006). 
We propose that these beliefs collectively form a distorted 'sexual offender schema' (i.e., a knowledge structure stored in memory; Fiske \& Taylor, 1984), which underpins people's evaluations of sexual offenders. That is, negative attitudes are formed, in part, because of the representation stored within a sexual offender schema. This proposition would imply that the label 'sexual offender' would be associated with this schematic representation (Harris \& Socia, 2014). Indeed, Harris and Socia found that when policies are framed using the label 'sex offenders' (as opposed to 'people who have committed crimes of a sexual nature'), community participants are more punitive in their policy support.

This proposition would also imply that individuals who reject social stereotypes about sexual offenders would hold more positive (or less negative) attitudes, as they are less likely to hold a biased sexual offender schema. Such individuals would include professionals. Indeed, numerous studies have found that forensic professionals tend to report less negative attitudes towards sexual offenders than non-professionals (Gakhal \& Brown, 2011; Higgins \& Ireland, 2009; Johnson, Hughes, \& Ireland, 2007; Kjelsberg \& Loos, 2008; Sanghara \& Wilson, 2006). In Sanghara and Wilson's study, experienced forensic professionals held more positive attitudes towards sexual offenders than non-experienced professionals (teachers). It was reported that this difference was due, in part, to the endorsement of fewer sexual offender stereotypes.

Attitudes towards sexual offenders are also correlated with sentencing judgments, with those expressing more negative views endorsing punitive policies (Brown, 1999; Harris \& Socia, 2014; Levenson, Brannon, Fortney, \& Baker, 2007; Nelson, Herlihy, \& Oescher, 2002; Shackley, Willis, \& Day, 2014). We propose that when making such judgments, members of the public automatically draw upon the sexual offender schema. As King and Roberts (2015) state, "when asked about "sex offenders" many are inclined to envision the media-proliferated stereotypical image of a violent, predatory male pedophile" (p. 2). This 
would mean that sentencing judgments made in the abstract (i.e., about sexual offenders in general) will be harsher than those made about a specific case that does not match the schema of a sexual offender (Salerno et al. 2010). In accordance with Harris and Socia (2014), we argue that judgments made about specific cases are thus guided by the representativeness heuristic (Tversky \& Kahneman, 1974).

The representativeness heuristic is an automatic mental process often employed when making judgments. It involves evaluating the degree to which $\mathrm{A}$ is similar to (or representative of) B. Thus, when making a sentencing judgment about a particular sexual offender (A), an individual may respond more harshly if the offender closely matches their sexual offender schema (B). Some previous studies provide support for this proposition. For example, Hogue and Peebles (1997) found that rapists who planned their offense (representative of a predatory offender) were judged more punitively that those acting impulsively. Craun and Theriot (2009) found that participants reported more concern about a child being sexually abused by an unknown individual (representative of a stranger sexual offender) than an individual known to them. In an undergraduate sample, Harper (2012) found that a juvenile sexual offender (i.e., not representative of the 'dirty old man' view) was judged less punitively than an adult male sexual offender (see also Study 3 in Salerno et al., 2010).

An important factor that can affect judgments and attitudes - which has received little attention in this field - is the influence of implicit theories about human attributes, as conceptualized by Dweck, Chiu, and Hong (1995a) ${ }^{1}$. According to this view, people tend hold one of two implicit theories (ITs) about human attributes: (1) entity ITs, where attributes are believed to be fixed, unchangeable, and dispositional, or (2) incremental ITs,

\footnotetext{
${ }^{1}$ This is conceptually different to the view of implicit theories as knowledge structures acquired through learning experiences and cultural influences (e.g., Sternberg, 1985).
} 
where attributes are believed to be malleable, fluid, and situational. Although some people hold an IT that cuts across domains, most people tend to hold domain-specific ITs (Dweck et al., 1995a). For example, someone may be an entitist with regards to intelligence (i.e., believing it is fixed) but an incrementalist with regards to creativity (i.e., believing it can be developed).

Importantly, Dweck, Chiu, and Hong (1995b) have found that "differences between entity and incremental theorists are not ascribable to differences in exposure to or knowledge of stereotypes" (p.329). In other words, an entitist and incrementalist can hold the same stereotype or schema within a specific domain but differ in how the stereotypic beliefs (or knowledge) are represented and organized in one's cognitive system. This will influence domain-specific judgments and reactions in manner that is consistent with one's framework, which may be influenced by an interaction between the sexual offender schema and wider ideological orientation (Dweck et al., 1995a).

In general, entitists tend to be more punitive towards moral transgressions, judging such behavior to be the result of dispositional factors. On the other hand, incrementalists tend to be less punitive, with transgressions viewed as being due to situational factors (Hong, 1994). Maruna and King (2009) examined the public's 'belief in redeemability' and found that participants who expressed a dispositional view of criminality (akin to an entity IT) were less likely to believe offenders can change and, thus, were more likely to support longer and harsher sentences. Participants who expressed a more situational view of criminality (akin to an incremental IT) displayed the opposite view. In a more specific examination of Dweck et al.'s IT dichotomy, Skitka, Mullen, Griffin, Hutchinson, and Chamberlin (2002) found that entity-based thinking about prisoners shaped the ways in which participants viewed the decision to parole certain offenders. That is, entitists suggested that offenders were freed due to institutional issues (e.g., overcrowding), while incrementalists suggested that release came 
as a result of personal change on the part of offenders. In addition, Skitka et al. found an interaction between IT classification and political ideology, with conservatives being more likely to hold entity ITs and liberals endorsing more incremental views.

Blagden, Winder, and Hames (2014) recently reported a moderate positive correlation between incremental ITs about sexual offending and attitudes towards sexual offenders. That is, as attitudes towards sexual offenders became more positive, so too did the belief in an offender's ability to change. These findings have important implications for treatment, since positive attitudes and a supportive therapeutic environment have been linked to successful outcomes in the treatment of sexual offenders (Beech \& Hamilton-Giachritsis, 2005).

With this in mind, addressing the influence of the public's ITs about sexual offenders is of great importance, as improvements in societal attitudes have been theoretically linked to an increased likelihood for sexual offenders to successfully reintegrate into the community and desist from offending (Willis et al., 2010). It is therefore crucial that we try to develop effective strategies that can effect attitude change in the public in order to: 1) improve the likelihood that released offenders will desist from offending, and 2) influence public policies that align with the current empirical literature (Levenson et al., 2007; Willis et al., 2010). We argue that examining the basic core assumptions (ITs) underlying people's attitudes towards sexual offenders and how they influence certain judgments is likely to be a valuable contribution to this end. However, no research to date has examined the interplay between ITs, attitudes towards sexual offenders, and judgments about sexual offenders in a community sample. This was the focus of the present study.

\section{The Present Study}

Based on the assumption that ITs underpin people's attitudes towards sexual offenders, our first aim was to examine whether attitudes towards sexual offenders differ 
depending on the type of IT someone holds about: (a) human nature, and (b) sexual offenders. A sub-aim was to establish the domain-specificity of ITs about sexual offenders by examining whether the magnitude of the difference between attitude scores was greater between entitists and incrementalists about sexual offenders, relative to that between entitists and incrementalists about human nature.

The second aim was based upon the theoretical assumption that people's judgment of a sexual offender will depend upon the interaction between one's IT about sexual offending and the representativeness of the offender. Thus, we aimed to examine whether entitists and incrementalists differ in their judgments about different types of sexual offenders; namely, an adult male, adult female, and male juvenile child abuser. A sub-aim here was to examine whether the explanation for the offender's behavior (i.e., dispositional or situational) corresponded with one's IT (i.e., entity versus incremental, respectively). In line with these aims, the following hypotheses were made:

H1: Participants who hold entity ITs will express more negative attitudes towards sexual offenders, as well as a more conservative political orientation, relative to those with incremental ITs. There will also be an association between tabloid newspaper readership and entity-based ITs about sexual offenders.

H2: Participants who hold entity ITs will judge a representative (i.e., adult male) sexual offender as being less moral than a non-representative (i.e., adult female, or juvenile) sexual offender, relative to those with incremental ITs.

H3: $\quad$ Participants who hold entity ITs will express more punitive sentencing responses when judging the representative case than when judging the nonrepresentative cases. 
H4: Participants who hold entity ITs will provide dispositional explanations for why a sexual offense was committed, whereas those with incremental ITs will provide a non-dispositional explanation.

Unlike some previous studies (e.g., King and Roberts, 2015), we chose to focus on one particular sexual offense (i.e., child sexual abuse) in order to allow for a better determination of whether the representativeness heuristic was at play. For example, if the entitists' advocate equally punitive sentencing judgments for all three child abusers (i.e., they are unaffected by the gender or age of the offender), then the idea that a schematic representation of a sexual offender can influence judgments would not be supported.

\section{Method}

\section{Participants}

The sample was comprised of 252 community-based participants (73 males, 177 females, 2 did not disclose their gender; $M_{\text {age }}=41.28$ years, $S D=15.25$ years), who were recruited online using social media announcements (via the authors' own Facebook and Twitter profiles), and email-driven invitations (via organizational and professional mailing lists). Advertisements invited participants to take part in the study, and to share the study link among their social networks. As such, opportunity and snowball sampling techniques were used, and participants were self-selecting. The only inclusion criterion in place was a lower age limit of 18. While an online survey restricts the extent to which the conditions of the experiment can be controlled, this approach was used such as to widen the potential participant pool and overcome limitations of studies that may be biased through the use of exclusively student or professional samples. 


\section{Materials}

Demographics. Participants were asked to indicate their sex, age, educational attainment level, and newspaper readership group. Additionally, participants were asked to respond to an 11-point continuous measure of their political stance, ranging from -5 (conservative) to +5 (liberal)

Implicit Theory Measures. Two short (three-item) self-report measures were used to assess specific ITs. The first was developed by Dweck et al. (1995) and assesses ITs about human nature (IT-HN; e.g., "Everyone is a certain kind of person and there is not much that can be done to really change that"). The second - adapted for the purpose of the present study - assessed ITs about the characteristics of sexual offenders (IT-SO; e.g., "Whether somebody commits a sexual crime is very much related to who they are as a person"). Participants rated their level of agreement to each statement using a six-point Likert scale ranging from 1 (strongly disagree) to 6 (strongly agree). Scores on both measures were averaged in order to produce a composite score for beliefs about that particular domain. Both measures demonstrated good internal reliability ( $\alpha$ 's $=.88$ and .74 , respectively).

Attitudes to Sexual Offenders Scale (ATS-21; Anonymous, in prep). The Attitudes to Sexual Offenders Scale (ATS; Hogue, 1993) is a 36-item self-report questionnaire. Each item is framed as an attitudinal statement about sexual offenders (e.g., 'Sex offenders are no better or worse than other people'), with participants rating their level of agreement with these statements on a 5-point Likert scale, scored from 0 (strongly disagree) to 4 (strongly agree). Anonymous (in prep) recently produced a shortened 21-item version of the ATS ('ATS-21'), which was used in this study. The ATS-21 correlates extremely highly with the original measure ( $r=.98, p<.001)$. It has three seven-item subscales ('Trust', 'Intent', and 'Social 
Distance'), and 11 items are reverse-scored. The ATS-21 has a scoring range of 0-84, with high scores indicating more positive attitudes. In the present study, the ATS-21 demonstrated excellent internal consistency $(a=.95)$, as did each of the subscales ('Trust' $\alpha=.89$; 'Intent' $\alpha=.88$; 'Social Distance' $\alpha=.84)$.

Vignettes. Three child sexual abuse vignettes were used as the experimental manipulation to examine the role of offender type on judgments of moral character and sentence severity. These vignettes were each approximately 200 words in length and described a sexual offense committed against a child of the opposite sex. The only manipulations between the three vignettes were demographic characteristics (i.e., the gender or age) of the perpetrator. That is, the vignette depicted an adult male, an adult female, or a male juvenile (aged 14 years) offender. Further, participants used 11-point Likert scales to judge: (a) the extent to which the offense was indicative of the moral character of the offender (anchored from $0=$ not at all indicative, to $10=$ very indicative); and (b) the type of sentence that they would recommend (anchored from $0=$ punishment, to $10=$ rehabilitation). In addition, participants were asked to provide a qualitative account as to why they felt the offense depicted in the vignette took place.

Perceptions of Sex Offenders Scale (PSO; Harper \& Hogue, 2015b). The PSO is a 20item self-report measure of sentencing, stereotype-consistent, and risk-based judgments about sexual offenders, with excellent levels of internal consistency (Harper \& Hogue, 2015a). This measure was included in the present research as an outcome measure for further ongoing investigations into the psychological mechanisms that underpin the relationship between affective evaluations (attitudes) about sexual offenders and policy-based judgments. As such, PSO data will not be discussed in this paper. 


\section{Procedure}

Potential participants were invited to take part in the study via an online survey, whose link was disseminated using the methods described previously. The survey software allowed us to ensure that only UK-based participants took part in the study, such as to control for potential extraneous culture-based variables. Those interested in taking part clicked on the link and were taken to the first page of the survey, which provided more detailed information about the study. If they were happy to continue, participants clicked a button that directed them to the demographic questionnaire.

From here, participants entered their demographic information and completed the ATS-21 and IT measures, before being randomly allocated by the survey software to either one of the vignette conditions. After reading their vignette, participants completed the associated questions, and finally completed the PSO. At the end of the survey, participants were fully debriefed about the nature and hypotheses of the study, and thanked for their time. The study received approval from an institutional review committee prior to data collection.

\section{Data Preparation}

For each IT measure, we followed the recommendations of Dweck et al. (1995a) to determine what type of IT each participant held. That is, participants with average scores of 1-3 were classified as 'incrementalists' (i.e., holding the view that general human nature/sexual offending is changeable over time). Participants with average scores of 4-6 were classified as 'entitists' (i.e., holding the view that human nature/sexual offending is stable and unchangeable). Participants whose IT score fell between the discrete values of 3 and 4 were excluded from subsequent analyses (IT-HN: $n=35$; IT-SO: $n=59$ ). With regards to implicit theories about human nature, 107 participants were classified as incrementalists 
and 110 as entitists. Regarding implicit theories about sexual offenders, 66 were classified as incrementalists and 127 as entitists.

\section{Results}

\section{Group Differences on Demographics, Political Ideology, and Attitudes Towards Sexual}

\section{Offenders}

IT-HN Differences. With regards to age, no group differences were found between ITHN incrementalists $\left(M_{\text {age }}=41.25, S D=14.87\right)$ and entitists $\left(M_{\text {age }}=40.51, S D=15.37\right)$. The groups also did not differ in terms of participant gender. In line with Hypothesis 1 , incrementalists were significantly more liberal $(M=1.70, S D=2.5)$ than entitists $(M=0.49$, $S D=2.61), t(215)=3.56, p<.001, d=0.47)$ and entitists reported significantly more negative attitudes towards sexual offenders $(M=35.83, S D=14.24)$ than incrementalists $(M$ $=48.58, S D=14.22), t(215)=6.60, p<.001, d=0.90)$. Significant group differences were also found on each subscale of the ATS-21, with this difference being most apparent in relation to the 'Trust' subscale (Table 1).

IT-SO Differences. There was a trend for IT-SO entitists to be older $\left(M_{\text {age }}=43.26, S D\right.$ $=15.23)$ than incrementalists $\left(M_{\text {age }}=38.98, S D=13.85\right)$. However, the difference was not significant $(p=.06)$. A trend was also observed with regards to gender, in that, more females $(n=93)$ were classified as entitists relative to males $(n=39)$. However, this difference failed to reach significance $(p=.08)$. Supporting Hypothesis 1 , incrementalists were significantly more liberal $(M=2.25, S D=2.30)$ than entitists $(M=0.59, S D=2.66), t(191)=4.27, p<$ $.001, d=0.68)$ and the entitists showed significantly more negative attitudes towards sexual offenders $(M=32.90, S D=12.50)$ than incrementalists $(M=56.80, S D=12.04), t(191)=$ $12.75, p<.001, d=1.95)$. As with the IT-HN groups, the two IT-SO groups also differed on 
all three ATS-21 subscales, with the greatest difference also being on the 'Trust' subscale. Further, the magnitude of the attitudinal differences between the IT-SO groups is far greater than those between than IT-HN groups (Table 1).

[Insert Table 1 here]

In order to examine the potential links between IT orientations about sexual offenders and newspaper readership, we conducted a chi-square test. We found a significant effect of newspaper readership group on IT-SO orientations $\left(\chi^{2}(3)=10.93, p=.012, \varphi=0.24\right)$. Examining this effect, exclusive tabloid readers were more likely to express entity ITs about sexual offenders $(n=39)$ than incremental ITs $(n=10)$. However, there were no differences in the frequency of entity and incremental ITs about sexual offenders among participants who exclusively read broadsheets ( $n=20$ vs. 21 ), or those who reported reading a combination of both publication types ( $n=17$ vs. 13 ).

\section{Influence of Implicit Theories on Judgments of Sexual Offenders.}

Owing to the apparent domain specificity of ITs about sexual offenders, only IT-SO scores were examined with regards to moral character and sentencing judgments about different types of sexual offenders.

Judgments of Moral Character. To test Hypothesis 2, a 2 (IT-SO: entity vs. incremental) x 3 (offender type: adult male vs. adult female vs. juvenile) independent ANOVA found significant main effects of 'offender type' $\left(F(2,135)=20.04, p<.001, \eta^{2}=\right.$ $0.03)$, and IT-SO group $\left(F(1,135)=21.99, p<.001, \eta^{2}=0.02\right)$, on judgments about the moral character of the perpetrators depicted in the vignettes. A significant interaction 
between IT-SO group and offender type was also observed $\left(F(2,135)=3.41, p=.036, \eta^{2}=\right.$ 0.01 ; Figure 1).

\section{[Insert Figure 1 Here]}

Simple main effects analyses, using the Bonferroni correction, found that IT-SO entitists provided significantly lower ratings of the offending behavior being indicative of the moral character of the perpetrator when presented with a juvenile than when the perpetrator was an adult male $(p<.001, d=1.28)$ or an adult female $(p=.001, d=0.93)$, providing partial support for Hypothesis 2. There was no difference in moral character judgments made by entitists between either of the adult-perpetrator vignettes $(p=.433)$. IT-SO incrementalists, however, provided significantly higher moral character judgments about the adult female perpetrator than the juvenile perpetrator $(p<.001, d=1.66)$. There were no differences in moral character judgments made by IT-SO incrementalists between the adult male and either the adult female $(p=.099)$, or the juvenile perpetrator $(p=.212)$. Descriptive data for these differences are provided in Table 2. Each of the significant differences had a large effect size.

[Insert Table 2 here]

Sentencing Judgments. To test Hypothesis 3, a 2 (IT-SO: entity vs. incremental) x 3 (offender type: adult male vs. adult female vs. juvenile) independent ANOVA found significant main effects of 'offender type' $\left(F(2,135)=6.00, p<.001, \eta^{2}=0.02\right)$, and sexual offender IT group $\left(F(1,135)=26.41, p<.001, \eta^{2}=0.04\right)$, with regards to sexual crime 
sentencing preferences. The interaction between these two independent variables was not statistically significant $\left(F(2,135)=1.96, p=.15, \eta^{2}=0.01 ;\right.$ Figure 2$)$.

[Insert Figure 2 Here]

Although no significant interaction between IT-SO grouping and offender type was found in relation to sentencing judgments, the differential trends in these judgments within each of the IT-SO groups (Table 2) warranted further analysis. Thus, two separate ancillary one-way independent measures ANOVAs were conducted for each IT-SO group in order to examine the differences in sentencing judgments between each of the vignettes.

Within the sample of IT-SO entitists, a medium main effect was found in relation to offender type $\left(F(2,92)=11.54, p<.001, \eta^{2}=0.07\right)$. Pairwise comparisons, with Bonferroni correction, found that this effect was due to differences (with medium-to-large magnitudes) in sentencing judgments between participants presented with the adult male vignette in comparison to both the adult female $(p=.018, d=0.71)$, and juvenile $(p<.001, d=1.17)$ vignettes. However, there was no significant difference between the sentencing judgments made by IT-SO entitists about the adult female and juvenile vignettes $(p=.222)$. Within the sample of IT-SO incrementalists, there was no effect of offender type $(F(2,43)=.95, p=$ .395), indicating that offender demographics played no role in moderating sentencing judgments among incrementalists. Collectively, these findings provide support for Hypothesis 3.

\section{Implicit Theories and Explanations for Sexual Offending}

Adapting previous research (Hong, 1994), the authors tested Hypothesis 4 by independently classifying the participants' qualitative explanations of the offending behavior 
as either: (1) 'dispositional' (i.e., where the behavior is viewed as a reflection of who the perpetrator is as an individual); (2) 'situational' (i.e., where external, situation-specific factors are viewed as integral to the commission of the offending behavior); or (3) 'N/A' (whereby a clear dichotomous classification was not possible). Initial inter-rater agreement was high $(\kappa=$ .87). After thorough discussion, we mutually agreed upon classifications for the explanations that were initially classified differently

Using a chi-square test, a significant effect of IT-SO group was found in relation to the explanations for the offending behavior depicted in the vignettes $\left(\chi^{2}(4)=14.01, p=.007\right.$, $\varphi=0.30)$. That is, entitsts were more likely to provide dispositional $(n=45)$ than situational explanations $(n=27)$, while incrementalists were more likely to offer situational $(n=25)$ than dispositional explanations $(n=8)$. This provided support for Hypothesis 4 .

A further series of chi-square tests were conducted to examine the differences in explanation style between the IT-SO groups for each vignette. In relation to the adult male offender, entitists offered predominantly dispositional explanations, and incrementalists were split between dispositional and situational explanations $\left(\chi^{2}(2)=12.64, p=.002, \varphi=0.56\right)$. The two groups did not differ, however, in relation to explanations of the offending behavior perpetrated by the adult female $\left(\chi^{2}(2)=5.12, p=.077\right)$. There was a marginally significant difference in explanatory trends for the juvenile-perpetrated offending $\left(\chi^{2}(2)=6.36, p=.042\right.$, $\varphi=0.39)$. In this case, all IT-SO incrementalists offered situational explanations, but a small number of entitists $(n=4)$ offered dispositional explanations.

\section{Discussion}

\section{Summary of Findings}

This study, using a community sample, primarily aimed to examine the influence that implicit theories have on: (1) self-reported attitudes towards sexual offenders, and (2) the 
judgments made about a representative and non-representative sexual offenders.. Supporting the first hypothesis, participants with entity ITs expressed more negative attitudes towards sexual offenders than incrementalists, as well as a more conservative political orientation. These differences were observed in relation to group differences on both of the IT measures. When comparing entitists and incrementalists on each ATS subscale (for both IT-HN and IT$\mathrm{SO})$, the greatest difference was found on the 'Trust' subscale. This suggests that because entitists view people (or sexual offenders) as being fixed in their ways, they are particularly more wary and untrusting of them compared to incrementalists.

The magnitude of these attitudinal differences between entitists and incrementalists were substantially larger when dividing the sample based on IT-SO scores than on IT-HN scores. This suggests that, although people with an incremental IT-HN have more positive attitudes towards sexual offenders than entitists, IT-SO incrementalists hold a stronger positive attitude. Moreover, fewer participants held an incremental view of sexual offenders ( $n=66)$ compared to those with an incremental view of human nature $(n=107)$. Also, slightly more people held an entity IT with regards to sexual offenders $(n=127)$ compared to entitists about human nature $(n=110)$. Furthermore, unlike the ITs about human nature, the two ITs about sexual offenders were not equally endorsed within the sample. This is an important observation because entity and incremental ITs are typically endorsed equally in most domains (Burnette, O'Boyle, VanEpps, Pollack, \& Finkel, 2013). We also found an increased rate of entity-based ITs about sexual offenders among readers of tabloid newspapers, but an equal split of entity and incremental ITs among broadsheet and 'mixed' readership groups. This finding is consistent with the view that offensive and dehumanized descriptions of sexual offenders (that are typically found in tabloid coverage; Harper \& Hogue, 2015a) may contribute to the development of entity ITs about this population. 
Collectively, these findings suggest that the ITs people hold about sexual offenders are independent of the ITs they hold about people more generally. This falls in line with the theoretical proposition that people hold a 'sexual offender schema' but make sense of it in an IT-consistent manner (Dweck et al., 1995b), as reflected in their surface-level attitudes (measured via the ATS-21). From this, it can be argued that an individual's IT influences what kind of response is appropriate when judging a particular sexual offender case.

This proposition is consistent with hypotheses two, three, and four, which our findings also support. That is, compared to IT-SO incrementalists, IT-SO entitists judged that sexual offending behavior was: (a) more indicative of the offender's moral character, and (b) more worthy of a punitive sentence. However, these differences in judgments were moderated by the 'type' of offender in the vignette. For example, IT-SO entitists viewed the offending behavior of both of the adult offenders as being significantly more indicative of their moral character but less so for the juvenile offender. IT-SO incrementalists, on the other hand, viewed the behavior of the adult female perpetrator as being more indicative of her moral character compared to the adult male or a juvenile offender. No differences were found between the adult male and juvenile offender.

As expected, IT-SO entitists also advocated more punishment-oriented sentences for each offender compared to the incrementalists. However, entitists supported significantly more punitive sentencing for the adult male offender than both the female and juvenile offenders. In contrast, IT-SO incrementalists consistently demonstrated a desire to see more rehabilitative sentences, with no differences in sentencing judgments between any of the three 'types' of sexual offenders. Across these results, the magnitudes of the differences were larger in relation to entity-related differences, again suggesting that entitists have a fixed idea of who a 'sexual offender' is when making their judgments. 
As expected, IT-SO entitists generally provided more dispositional (comparative to situational) explanations for the offending behavior depicted in the vignettes than did incrementalists. When examining the explanations provided for offending behavior of each offender, no strong group differences were found for either the adult female or juvenile offender. However, entitists were significantly more likely to offer dispositional explanations for the offending behavior of the adult male, relative to incrementalists.

\section{The Foundations of Implicit Theories about Sexual Offenders}

Participants' responses to the vignettes presented in this study provide early evidence that entity ITs about sexual offenders may be based on the representativeness heuristic (Tversky \& Kahneman, 1974), whereas judgments made by those with incremental ITs may be based on other, perhaps more general, ideological factors.

Although IT-SO entitists suggested that sexually offending behavior is more indicative of the moral character of a perpetrator (compared to the judgments expressed incrementalists), the size of this difference was largest when the perpetrator was an adult male. The next largest difference between the two IT-SO groups was found in relation to the juvenile perpetrator, with no significant difference found in moral character judgments between these groups in relation to the adult female perpetrator. This hierarchical effect was also present within IT-SO entitists' sentencing judgments, with these participants expressing differential sentencing preferences in relation to the adult male perpetrator (most punitive preferences), through the adult female perpetrator, and to the juvenile perpetrator of sexual assault (least punitive).

This hierarchical trend in moral character and sentencing judgments may also be indicative of the extent to which IT-SO entitists endorse the notion that some perpetrators of sexual violence are 'sexual offenders' at all. That is, if IT-SO entitists have a narrow view of 
who a 'sexual offender' is likely to be (i.e., an adult male), then it follows that the most punitive judgments will be made in response to this group. The intermediate placement of the judgments about adult female offenders (i.e., between the views about the adult male and juvenile) is also consistent with a narrow (i.e., 'representativeness') view of sexual crime, although in a more general sense (i.e., she is an adult). The coverage of child sexual abuse within the mainstream media is typically made up of offenses perpetrated by adults, rather than juveniles (Harper \& Hogue, 2014). By viewing the adult female in a more punitive way than the juvenile perpetrator, IT-SO entitists are endorsing the view that adult offenders are more 'deserving' of the 'sexual offender' label than the juvenile, based upon their idea of what a sexual offense should look like.

However, this representativeness effect does not appear to be affecting the judgments of the IT-SO incrementalists. Instead, these participants hold relatively stable views with regard to moral character and sentencing judgments across all child abuser types. The one exception to this consistency was the inflated moral character judgments made by IT-SO incrementalists in relation to the adult female. This may be attributable to the phenomenon of double deviance (Heidensohn, 1985). That is, by committing a sexual offense against a child, the adult female perpetrator had not only acted in a deviant way through the commission of a sexual offense, but doubly so by violating the socially-traditional caregiver role. The consistency in sentencing judgments among IT-SO incrementalists across the three vignette conditions, however, is consistent with the view that offending behavior can change over time.

Analyses of the participants' qualitative explanations for sexual offending also provide evidence for representativeness-based judgments. Specifically, IT-SO entitists were significantly more likely to provide dispositional explanations when presented with an adult male offender than when presented with a juvenile perpetrator (for which they were more 
likely to provide situational explanations). Again, explanations for adult female's offending behavior fell in between these two extremes. In comparison, incrementalists were more likely, in all cases, to offer situational rather than dispositional explanations. In combination, these findings are all consistent with the theoretical proposition that IT-SO entitists hold a specific 'sexual offender schema' in mind, which influences their judgments about different 'types' of offenders.

\section{Limitations}

While these finding provide a theoretical advance in this area, some limitations need addressing in future work. First, a comparison condition (or vignette) describing an offense by a non-sexual offender was not included. One would expect IT-SO entitists to judge a nonsexual offender less severely as it would not be representative of a prototypical sexual offender. This would further substantiate the claim that a sexual offender schema is influencing entitists' judgments. Thus, this warrants further investigation. Similarly, vignettes describing other types of child abusers that do not fit the sexual offender schema were not included, such as an incest offender, an intellectually disabled offender, or an internet sex offender. Thus, investigating the public's judgments of other non-representative offenders would make for a useful follow-up study. There is also a lack of literature on female juvenile sexual offenders (though see Wijkman, Bijleveld, \& Hendriks, 2014). In the present study we only incorporated a male juvenile perpetrator vignette, owing to this shortage of literature. However, examining judgments of this under-studied group in future work would aid a fuller understanding of the interactions between age and gender. Also of note, in relation to gender issues, is the disproportionate split of males and females in our sample. This may introduce some level of bias when judging male and female sexual offenders, highlighting another issue to address in future research. 
Second, following Dweck et al.'s (1995a) recommendation, both of the continuous IT measures were dichotomized to produce two the entitist and incrementalist groups. As such, the IT aspect of the study was cross-sectional in nature. Therefore, no strong conclusions can be made that holding an entity IT causes one to judge sexual offenders more harshly than incrementalists. Other IT researchers have addressed the issue of causality by experimentally inducing or priming a particular IT (Hong, Chiu, Dweck, Lin, \& Wan, 1999; Yorkston, Nunes, \& Matta, 2010). Therefore, to directly test the hypothesis that ITs cause differential judgments towards sexual offenders, future research should aim to experimentally manipulate participants' view of sexual offending behavior.

Third, we did not directly test for whether the participants held a media-proliferated sexual offender schema. Thus, future research could test whether the punitive judgments made by entitists are mediated by the endorsement of a sexual schema/stereotype.

\section{Future Directions}

The results of this study have implications for how to address attitudes towards sexual offenders. Since IT-SO entitists were found to believe that sexual offenders' behavior and character was fixed and dispositional, it may not be enough to simply educate people in an attempt to change their biased 'knowledge' about sexual offenders. We argue that researchers and practitioners should also examine what type of IT each person holds. Those found to hold an entity IT may need to be aided in how think incrementally. As mentioned above, incremental ITs have been experimentally induced, suggesting that a default entitist could be trained to alter their view of sexual offenders in a more incremental manner. Thus, researchers and practitioners should aim to develop training strategies with this in mind.

Previous researchers have found that training can be effective in improving the knowledge and attitudes of professionals' and paraprofessionals' working with sexual 
offenders (Craig, 2005; Hogue, 1994). As shown by Blagden et al. (2014), professionals who work therapeutically with sexual offenders generally hold incremental ITs. Future research should examine these concepts further in order to establish whether professionals' ITs have an effect on the efficacy of sexual offender training. Arguably, additional strategies may need to be implanted into training programs for those holding an entitist IT in order to improve levels of effectiveness. It should be noted that the results from Blagden et al.'s study cannot assert whether the professionals' incrementality existed before they worked in this field, or formed as a result of their exposure to non-stereotypical sexual offenders. This would also be interesting to examine.

In this study, we examined ITs in terms of Dweck et al.'s (1995a) entity and incrementality dichotomy. These two forms of IT are thought to provide a framework for how knowledge structures (e.g., schemas, stereotypes) are made sense of, which in turn influences judgments. Other researchers, however, have focused on ITs as non-conscious knowledge structures (containing a constellation of beliefs) about specific people, events, objects, and psychological constructs that reside in people's minds (e.g., Sternberg, 1985). These types of ITs are seen as being acquired or discovered through experience and cultural influences. Drawing on this approach, McCartan (2010) investigated students' and traineeprofessionals' ITs about pedophiles. He found that the content of these ITs contained the view that pedophiles are abnormal, devious, older, sexually deviant offenders who engage in child-focused grooming behaviors. An issue with McCartan's study is that he explicitly asked participants "What is a paedophile?" and "What attitudes and behaviours do paedophiles typically display?” (p. 269). Therefore, his findings most likely demonstrate the explicit, surface-level beliefs that the participants held. As such, they mirror the 'myths' found in prior research, and partially support our argument that people hold a general sexual offender schema that they can bring to mind when asked. However, it is possible that these surface- 
level views are underpinned by a deeper, underlying cognitive structure that is more akin to an 'implicit theory-as-knowledge structure'. Thus, this would be a highly interesting area for future researchers to investigate.

\section{Concluding Remarks}

This paper found evidence of domain-specific ITs about sexual offenders, with these being linked to differential judgments about three different types of child sexual abusers. These findings suggest that entity ITs about sexual offenders may be based upon a schema of who or what a 'sexual offender' is (in the broadest sense). The causes of such schemas may be numerous, although there is a responsibility on media outlets, policy-makers, and academics to disseminate accurate information about the true nature of sexual offending in order to dispel social myths and misunderstandings that may exist at a societal level. This first examination of the role that entity and incremental ITs play in moderating people's responses to sexual crime highlights an untested and potentially fruitful area for further research. 


\section{References}

Beech, A. R., \& Hamilton-Giachritsis, C. E. (2005). Relationship between therapeutic climate and treatment outcome in group-based sexual offender treatment programmes. Sexual Abuse: A Journal of Research and Treatment, 17, 127-140.

doi: 10.1007/s11194-005-600-3.

Blagden, N., Winder, B., \& Hames, C. (2014). "They treat us like human beings" experiencing a therapeutic sex offenders prison impact on prisoners and staff and implications for treatment. International Journal of Offender Therapy and Comparative Criminology. Advance online publication. doi:10.1177/0306624X14553227.

Brown, S. (1999). Public attitudes toward the treatment of sex offenders. Legal and Criminological Psychology, 4, 239252. doi:10.1348/135532599167879.

Burnette, J. L., O'Boyle, E. H., VanEpps, E. M., Pollack, J. M., \& Finkel, E. J. (2013). Mindsets matter: A meta-analytic review of implicit theories and self-regulation. Psychological Bulletin, 139, 655-701. doi: 10.1037/a0029531.

Clore, G. L., Gasper, K., \& Garvin, E. (2001). Affect as information. In J. P. Forgas (Ed.), Handbook of affect and social cognition (pp. 121-144). Mahwah, NJ: Erlbaum.

Craig, L. A. (2005). The impact of training on attitudes towards sex offenders. Journal of Sexual Aggression, 11, 197-207. doi:10.1080/13552600500172103.

Crano, W. D., Cooper, J., \& Forgas, J. P. (2010). Attitudes and attitude change. An introductory review. In J. P. Forgas, J. Cooper, \& W. D. Crano (Eds.), The psychology of attitudes and attitude change (pp. 3-18). New York, NY: Psychology Press.

Craun, S. W., \& Theriot, M. T. (2009). Misperceptions of sex offender perpetration: Considering the impact of sex offender registration. Journal of Interpersonal Violence, 24, 2057-2072. doi:10.1177/0886260508327706. 
Cromer, L. D., \& Goldsmith, R. E. (2010). Child sexual abuse myths: Attitudes, beliefs, and individual differences. Journal of Child Sexual Abuse, 19, 618-647, doi:10.1080/10538712.2010.522493.

Dweck, C. S., Chiu, C., \& Hong, Y. (1995a). Implicit theories and their role in judgments and reactions: A world from two perspectives. Psychological Inquiry, 6, 267-285. doi:10.1207/s15327965pli0604_1.

Dweck, C. S., Chiu, C., \& Hong,Y. (1995b). Implicit theories: Elaboration and extension of the model. Psychological Inquiry, 6, 322-333. doi:10.1207/s15327965pli0604_12.

Fedoroff, P. J., \& Moran, B. (1997). Myths and misconceptions about sex offenders. The Canadian Journal of Human Sexuality, 6, 263-276. Retrieved from: http://www.taasa.org/library/pdfs/TAASALibrary108.pdf.

Fiske, S. T., \& Taylor, S. E. (1984). Social cognition. Reading, MA: Addison-Wesley.

Fuselier, D. A., Durham, R. L., \& Wurtele, S. K. (2002). The child sexual abuser: Perceptions of college students and professionals. Sexual Abuse: A Journal of Research \& Treatment, 14, 267-276. doi:10.1177/107906320201400306.

Gakhal, B., \& Brown, S. J. (2011). A comparison of the general public's, forensic professionals' and students' attitudes towards female sex offenders. Journal of Sexual Aggression, 17, 105-116. doi:10.1080/13552600.2010.540678.

Galeste, M., Fradella, H., \& Vogel, B. (2012). Sex offender myths in print media: Separating fact from fiction in U.S. newspapers. Western Criminology Review, 13, 4-24. Retrieved from: http://www.westerncriminology.org/documents/WCR/v13n2/v13n2.pdf.

Greer, C. (2012). Sex crime and the media: Sex offending and the press in a divided society. Abingdon, UK: Routledge.

Harper, C. A. (2012). In pursuit of the beast: Undergraduate attitudes towards sex offenders and implications for society, rehabilitation, and British psychology education. Internet 
Journal of Criminology. Retrieved from:

http://www.internetjournalofcriminology.com/Harper_In_Pursuit_of_the_Beast_IJC_July _2012.pdf.

Harper, C. A., \& Hogue, T. E. (2014). A prototype-willingness model of sexual crime discourse in England and Wales. The Howard Journal of Criminal Justice, 53, 511-524. doi: 10.1111/hojo.12095.

Harper, C. A., \& Hogue, T. E. (2015a). The emotional representation of sexual crime in the national British press. Journal of Language and Social Psychology, 34, 3-24. doi: 10.1177/0261927X14544474.

Harper, C. A., \& Hogue, T. E. (2015b). Measuring public perceptions of sex offenders: reimagining the Community Attitudes Toward Sex Offenders (CATSO) scale. Psychology, Crime \& Law, 21, 452-470. doi: 10.1080/1068316X.2014.989170.

Harris, A. J., \& Socia, K. M. (2014). What's in a name? Evaluating the effects of the "sex offender" label on public beliefs and opinions. Sexual Abuse: A Journal of Research and Treatment. Advance online publication. doi: 10.1177/1079063214564391.

Haidt, J. (2012). The righteous mind: How good people are divided by politics and religion. London, UK: Penguin.

Heidensohn, F. (1985). Women and crime. London, UK: Macmillan Press.

Higgins, C., \& Ireland, C. A. (2009). Attitudes towards male and female sex offenders: a comparison of forensic staff, prison officers and the general public in Northern Ireland. British Journal of Forensic Practice, 11, 14-19. doi: 10.1108/14636646200900004.

Hogue, T. E. (1993). Attitudes towards prisoners and sex offenders. In N. C. Clark and G. Stephenson (Eds.). DCLP Occasional Papers: Sexual Offenders. Leicester, UK: British Psychological Society. 
Hogue, T. E. (1994). Training multi-disciplinary teams to work with sex offenders: Effects on staff attitudes. Psychology, Crime \& Law, 1, 227-235. doi: 10.1080/10683169508411958.

Hogue, T. E., \& Peebles, J. (1997). The influence of remorse, intent and attitudes toward sex offenders on judgments of a rapist. Psychology, Crime \& Law, 3, 249-259.

doi: 10.1080/10683169708410821.

Hong, Y. (1994). Predicting trait versus process inferences: The role of implicit theories. Unpublished doctoral dissertation. Columbia University.

Hong, Y. Y., Chiu, C. Y., Dweck, C. S., Lin, D. M. S., \& Wan, W. (1999). Implicit theories, attributions, and coping: A meaning system approach. Journal of Personality and Social Psychology, 77, 588-599. doi: 10.1037/0022-3514.77.3.588.

Johnson, H., Hughes, J., \& Ireland, J. (2007). Attitudes towards sex offenders and the role of empathy, locus of control and training: a comparison between a probationer police and general public sample. The Police Journal, 80, 28-54. Retrieved from: http://heinonline.org/HOL/LandingPage?handle=hein.journals/policej180\&div=6\&id=\&pa ge $=$.

Kernsmith, P. D., Craun, S. W., \& Foster, J. (2009). Public attitudes towards sexual offenders and sex offender registration. Journal of Child Sexual Abuse, 18, 290-301. doi: $10.1080 / 10538710902901663$.

King, L. L., \& Roberts, J. J. (2015). The complexity of public attitudes toward sex crimes. Victims \& Offenders. Advance online publication. doi: 10.1080/15564886.2015.1005266 Kjelsberg, E., \& Loos, L. (2008). Conciliation or condemnation? Prison employees' and young peoples' attitudes towards sexual offenders. The International Journal of Forensic Mental Health, 7, 95-103. doi: 10.1080/14999013.2008.9914406.

Lakoff, G. (2014). The all-new “don't think of an elephant”: Know your values and frame the debate. White River Junction, VT: Chelsea Green Publishing. 
Levenson, J. S., Brannon, Y. N., Fortney, T., \& Baker, J. (2007). Public perceptions about sex offenders and community protection policies. Analyses of Social Issues and Public Policy (ASAP), 7, 137-161. doi: 10.1111/j.1530-2415.2007.00119.x.

Malinen, S., Willis, G. W., \& Johnston, L. (2014). Might informative media reporting of sexual offending influence community members' attitudes towards sex offenders? Psychology, Crime \& Law, 20, 535-552. doi: 10.1080/1068316X.2013.793770.

Maruna, S., \& King, A. (2009). Once a criminal, always a criminal? 'Redeemability' and the psychology of punitive public attitudes. European Journal of Criminal Policy Research, 15, 7-24. doi: 10.1007/s10610-008-9088-1.

McCartan, K. F. (2010). Student/trainee-professional implicit theories of paedophilia. Psychology, Crime \& Law, 16, 265-288. doi: 10.1080/10683160802614144.

McCartan, K. F., Kemshall, H., \& Tabachnick, J. (2015). The construction of community understandings of sexual violence: rethinking public, practitioner and policy discourses. Journal of Sexual Aggression, 21, 100-116. doi: 10.1080/13552600.2014.945976.

Nelson, M., Herlihy, B., \& Oescher, J. (2002). A survey of counsellor attitudes towards sex offenders. Journal of Mental Health Counseling, 24, 51-67. Retrieved from: http://www.biomedsearch.com/article/survey-counsellor-attitudes-towardssex/83032627.html.

Olver, M. E., \& Barlow, A. A. (2010). Public attitudes toward sex offenders and their relationship to personality traits and demographic characteristics. Behavioral Sciences \& The Law, 28, 832-849. doi: 10.1002/bsl.959.

Quinn, J. F., Forsyth, C. J., \& Mullen-Quinn, C. J. (2004). Societal reaction to sex offenders: A review of the origins and results of the myths surrounding their crimes and treatment amenability. Deviant Behavior, 25, 215-232. doi: 10.1080/01639620490431147. 
Rogers, D L., \& Ferguson, C. J. (2011). Punishment and rehabilitation attitudes towards sex offenders versus nonsexual offenders. Journal of Aggression, Maltreatment, \& Trauma, 20, 395-414. doi: 10.1080/10926771.2011.570287.

Rogers, P., Hirst, L., \& Davies, M. (2011). An investigation into the effect of respondent gender, victim age, and perpetrator treatment on public attitudes towards sex offenders, sex offender treatment, and sex offender rehabilitation. Journal of Offender Rehabilitation, 50, 511-530. doi: 10.1080/10509674.2011.602472.

Sanghara, K. K., \& Wilson, J. (2006). Stereotypes and attitudes about child sexual abusers: A comparison of experienced and inexperienced professionals in sex offender treatment. Legal and Criminological Psychology, 11, 229-244. doi: 10.1348/135532505X68818.

Salerno, J. M., Najdowski, C. J., Stevenson, M. C., Wiley, T. R., Bottoms, B. L., Vaca, R., \& Pimentel, P. S. (2010). Psychological mechanisms underlying support for juvenile sex offender registry laws: Prototypes, moral outrage, and perceived threat. Behavioral Sciences \& the Law, 28, 58-83. doi: 10.1002/bsl.921.

Shackley, M., Weiner, C., Day, A., \& Willis, G. W. (2014). Assessment of public attitudes towards sex offenders in an Australian population. Psychology, Crime \& Law, 20, 553572. doi: 10.1080/1068316X.2013.793772.

Skitka, L. J., Mullen, E., Griffin, T., Hutchinson, S., \& Chamberlin, B. (2002). Dispositions, scripts, or motivated cognition? Understanding ideological differences in explanations for social problems. Journal of Personality and Social Psychology, 83, 470-487. doi: 10.1037//0022-3514.83.2.470.

Thakker, L. (2012). Public attitudes to sex offenders in New Zealand. Journal of Sexual Aggression, 18, 149-163. doi: 10.1080/13552600.2010.526245.

Tversky, A., \& Kahneman, D. (1974). Judgement under uncertainty: Heuristics and biases. Science, 185, 1124-1131. doi: 10.1126/science.185.4157.1124. 
Vess, J. (2009). Fear and loathing in public policy: Ethical issues in laws for sex offenders. Aggression and Violent Behavior, 14, 264-272. doi: 10.1177/1079063210382045.

Wijkman, M., Bijleveld, C., \& Hendriks, J. (2014). Juvenile female sex offenders: Offender and offence characteristics. European Journal of Criminology, 11, 23-38. doi: $10.1177 / 1477370813479077$.

Willis, G. M., Levenson, J. S., \& Ward, T. (2010). Desistance and attitudes towards sex offenders: Facilitation or hindrance? Journal of Family Violence, 25, 545-556. doi: 10.1007/s10896-010-9314-8.

Willis, G. M., Malinen. S., \& Johnston, L. (2013). Demographic differences in public attitudes towards sex offenders. Psychiatry, Psychology, and Law, 20, 230- 247. doi: 10.1080/13218719.2012.658206.

Yorkston, E. A., Nunes, J. C., \& Matta, S. (2010). The malleable brand: The role of implicit theories in evaluating brand extensions. Journal of Marketing, 74, 80-93. doi: 10.1509/jmkg.74.1.80. 
Table 1: Means, standard deviations, and group differences on each ATS-21 subscale

\begin{tabular}{|c|c|c|c|c|c|c|c|c|c|}
\hline & \multicolumn{2}{|c|}{ IT-HN Group } & $t$ & $p$ & $d$ & IT-SO Group & $t$ & $p$ & $d$ \\
\hline $\begin{array}{l}\text { ATS-21 } \\
\text { subscale }\end{array}$ & Entitist & Incrementalist & & & & Incrementalist & & & \\
\hline Trust & $7.90 \quad(5.21)$ & $12.81 \quad(5.87)$ & 6.52 & $<.001$ & 0.88 & $16.59(5.01)$ & 13.75 & $<.001$ & 2.04 \\
\hline Intent & $15.47(5.60)$ & $19.71 \quad(4.3)$ & 6.19 & $<.001$ & 0.85 & $14.62(4.99)$ & 11.43 & $<.001$ & 1.66 \\
\hline $\begin{array}{l}\text { Social } \\
\text { distance }\end{array}$ & $12.45(4.69)$ & $16.04(5.05)$ & 5.45 & $<.001$ & 0.74 & $18.27(4.37)$ & 10.08 & $<.001$ & 1.55 \\
\hline
\end{tabular}

Note: ATS-21 = Attitudes Towards Sexual Offenders -short-form; IT-HN = Implicit theories about human nature; IT-SO = Implicit theories about sexual offenders 
Table 2: Differences in moral character and sentencing judgments as a function of IT classification and offender type

\begin{tabular}{|c|c|c|c|c|c|c|}
\hline \multirow[b]{2}{*}{ IT-SO Group } & \multicolumn{3}{|c|}{ Moral character scores $(S D)$} & \multicolumn{3}{|c|}{ Sentencing judgments $(S D)$} \\
\hline & Male & Female & Juvenile & & Female & Juvenile \\
\hline Entitist & $8.13(1.95)$ & $7.34(2.00)$ & $5.19(2.60)$ & $2.80(2.60)$ & $4.73(2.80)$ & $6.04(2.92)$ \\
\hline Incrementalist & $4.91(2.50)$ & $6.76(2.08)$ & $3.35(2.02)$ & $6.71(2.49)$ & $6.68(2.46)$ & $7.65(2.04)$ \\
\hline
\end{tabular}

Note: Higher moral character scores indicate offending perceived as indicative of character; Higher sentencing scores are indicative of a desire to rehabilitate (vs. punish). Among those receiving the adult male vignette, 37 participants were entitists, while 10 were incrementalists. Among those receiving the adult female vignette, 29 participants were entitists, while 18 were incrementalists. Among those receiving the juvenile vignette, 29 participants were entitists, while 18 were incrementalists. 


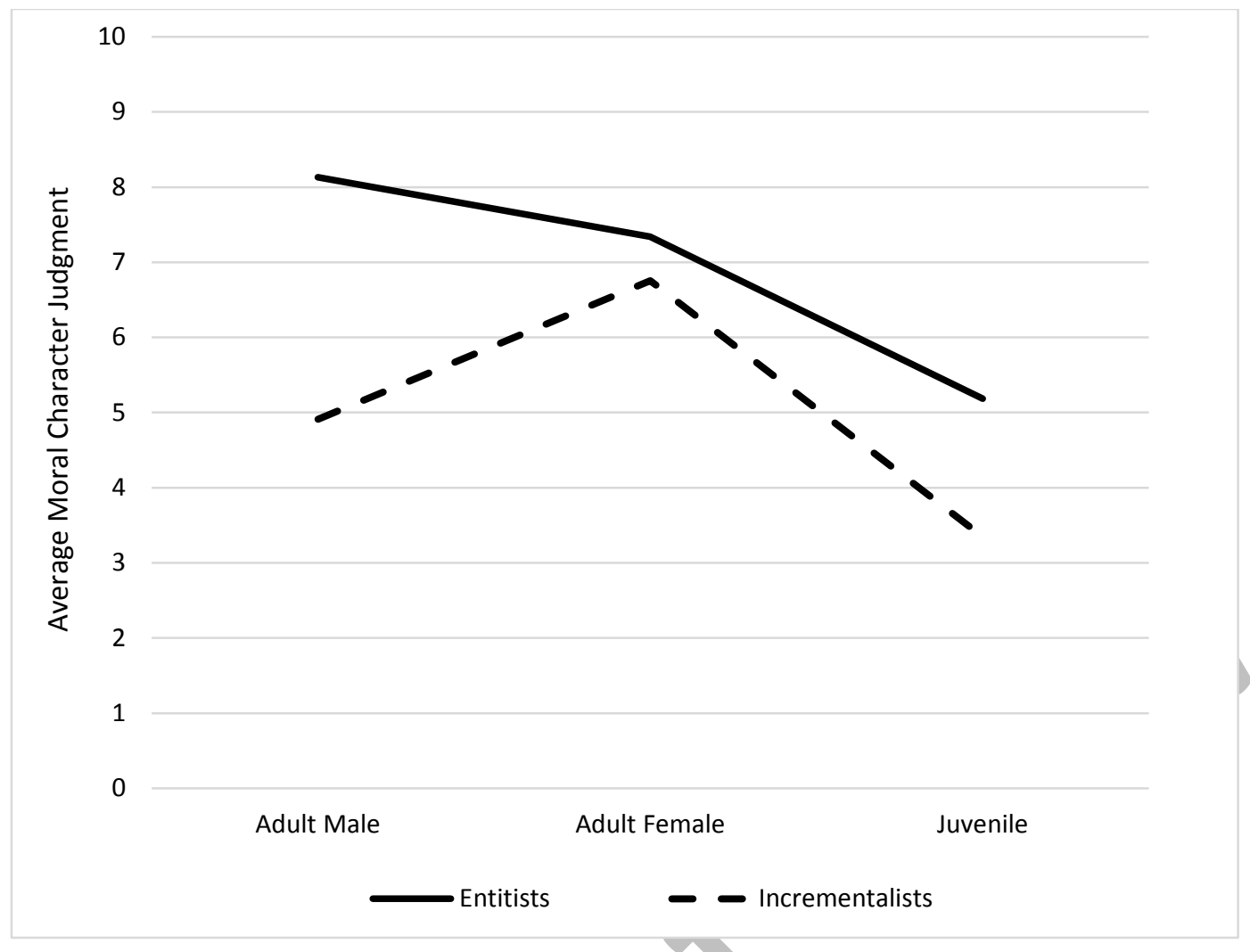

Figure 1: Interaction effect between offender type and IT-SO grouping in relation to judgments of an offender's moral character 


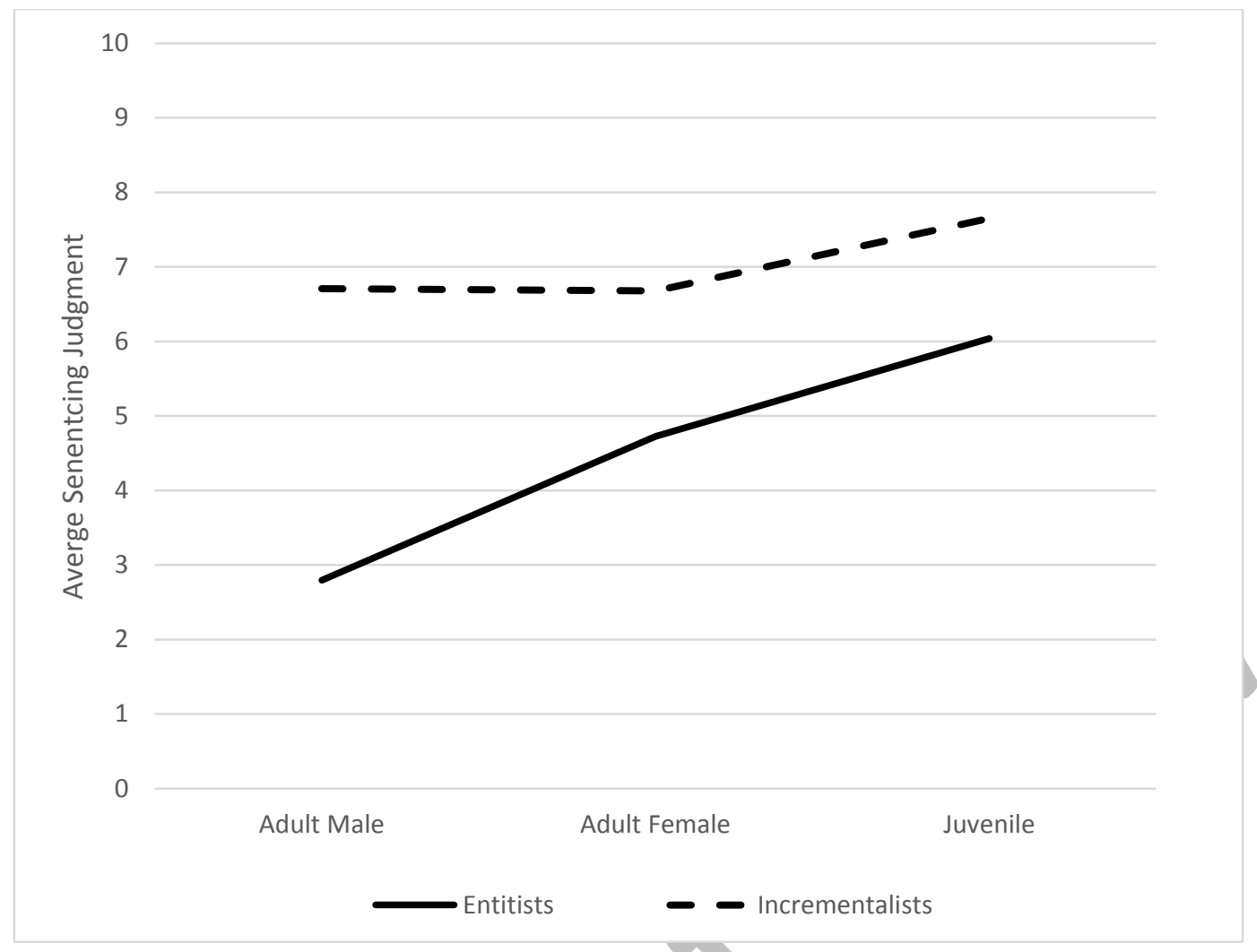

Figure 2: Interaction effect between offender type and IT-SO grouping in relation to sentencing judgments 